\title{
Attention Bias to Sad Faces and Images: Which Is Better for Predicting Depression?
}

\author{
Bita Ajilchi ${ }^{1 *}$, Vahid Nejati ${ }^{2}$ \\ ${ }^{1}$ Department of Psychology, Faculty of Human Science, Science and Research Branch University, \\ Islamic Azad University (IAU), Tehran, Iran \\ ${ }^{2}$ Department of Psychology, Faculty of Human Science, Shahid Beheshti University, Tehran, Iran \\ Email: Ajilchi_b@yahoo.com
}

Received June $7^{\text {th }}, 2013$; revised July $7^{\text {th }}, 2013$; accepted July $15^{\text {th }}, 2013$

\begin{abstract}
Copyright (C) 2013 Bita Ajilchi, Vahid Nejati. This is an open access article distributed under the Creative Commons Attribution License, which permits unrestricted use, distribution, and reproduction in any medium, provided the original work is properly cited.
\end{abstract}

\begin{abstract}
This study aims to compare emotion face and emotion image dot-probe tasks in predicting depression. The study uses descriptive correlational methods. The subjects studied during the research included the people between the ages of 19 - 40 years, who visited a particular psychology clinic in Tehran, Iran from 2011 to 2012. The patients studied received a clinical diagnosis, based on an unstructured interview, as per the 4th Edition of Diagnostic and Statistical Manual of Mental Disorders (DSM-IV), and a screening test using the Beck Depression Inventory (BDI, cut off point 21 and higher). Then 82 individuals were selected, using the convenience sampling method. Two computerized dot-probe tasks (emotional faces and images) were administered to the participants. Pearson's correlation coefficients and univariate regression analysis showed that, in both tasks, attention bias was significantly linked with depression and could predict it $(P<0.01)$. Fisher's Z-test further showed that the emotion face dot-probe task could predict depression more precisely than the emotion image dot-probe task $(P<0.01)$.
\end{abstract}

Keywords: Attention Bias; Dot-Probe Task; Emotional Face; Emotional Image; Depression

\section{Introduction}

Poor social performance is considered the most recognizable characteristic of a depressive disorder. (Levendosky, Okun, \& Parker, 1995). Relevant literature indicates that people, who suffer from depression, fail to establish efficient interpersonal interactions (Wang, Wang, Chen, Zhu, \& Wang, 2008). Thus, patients with depression have a poor comprehension of social situations (Beevers, 2009) and they face problems in interpreting interpersonal information, such as emotions and facial expressions (Bouhuys, Bloem, \& Groothuis, 1995). Deficiency in establishing social interactions plays a key role in the development of a depressive disorder (Kerr, Dunbar, \& Bentall, 2003; Inoue, Tonooka, Yamada, \& Kanba, 2004, cited in Nejati, Zabihzadeh, Maleki, \& Mohseni, 2012). It seems that the cognitive infrastructures of this vicious circle must be thoroughly investigated in depressed people. Cognitive theories, relating to depression, (Beck Depression Inventory (BDI), 1976; Teazdale, 1988) say that this disorder of attention bias begins to manifest itself in the form of depression, in relevant cases. In line with these theories, several studies showed that depressed people exhibit selective attention towards negative stimuli, even after their recoveries. (Fritzch et al., 2010; Leung, Lee, Yip, Li, \& Wong, 2009; Staugaard, 2009; Peckman, McHugh, \& Otto, 2010).

Several researchers have described that this selective attention, towards sad stimuli, as being neither caused by depression nor is it considered as a symptom, but rather it plays a major

\footnotetext{
"Corresponding author.
}

role in the onset and development of depression. Many researchers discovered that cognitive attention biases towards processing emotional information, particularly sad stimuli, not only make the individual vulnerable to depression and cause sustained depressive symptoms, but also that they could develop a depressive mood, even in those, who have recovered from depression (Beevers \& Carver, 2003; Wells \& Beevers, 2009). Baert et al. (2010), Joormann \& Gotlibe (2007), Segal, Gemar, \& Williams (1999), Macleod \& Mathews (1991), Williams \& Oaksford (1992) and Beck (2008).

The dot-probe task is one of the main tools used in diagnosing of attention bias in depressive disorders. The task, originally developed by MacLeod, Mathews \& Tata (1986), showed that people respond faster to probes when they are presented inside the field of awareness rather than outside of it (Chen, Ehlers, Clark, \& Mansell, 2002). Instead of neutral and positive stimuli, the task makes use of sad and emotional stimuli to diagnose attention bias. The nature of the stimuli differs according to the nature of the task.

Macleod et al. (1986) originally used words in developing the dot-probe task, but the procedure was then continued by Beevers and Carver (2003), Koster, De Raedt, Goeleven, Frank, $\&$ Crombez (2005), Leung et al. (2009) and Baert et al. (2010). Later, the use of human faces, rather than words, became popular. The practice was based on the logic that biologically, human beings may reconstruct emotional facial expressions, even during a state of unconsciousness. Dimberg, Thunberg, \& Elmehed, 2000; Bradley, Mogg, Falla, \& Hamilton (1998) found that the face indicates real situations better than words do 
(Mogg \& Bradley, 2002). The face is considered as a social stimulus that could profoundly affect an attention bias. Fox, Lester, Russo, Bowles, Pichler, \& Dutton (2000), Koster, Leyman, Raedt, \& Crombez (2006) showed that the face could transfer much important social and biological information such as identity, gender, age, emotional state and attractiveness (Chaleypanloo, Garoosi Farshi, \& Ghenaat Pisheh, 2010).

Koster et al. (2006), Leyman, De Raedt, Schacht, \& Koster (2006), Staugaard (2009) and Fritzch et al. (2010), also used human faces as stimuli in studying attention bias. The emotional images lately used in dot-probe tasks, instead of words, showed that this kind of stimuli could create attention bias by arousing the individual's selective attention (Schmukle, 2005; Wells \& Beevers, 2009; Sears, Newman, Ference, \& Thomas, 2011). Browning, Holmes, Charles, Cowen, \& Hamer (2012) employed two kinds of stimuli, i.e. both words and faces, and Schmukle (2005) studied word and emotional images as the stimuli. Compared to normal people, depressed individuals show a negative attention bias when encountering key social states, such as facial expressions (Gur, Erwin, Gur, Zwil, Heimberg, \& Kraemer, 1992; Bouhuys, Geerts, \& Gordijn, 1999). This attention bias is linked to increased responses in the nerve network, which is involved in emotional processing. In comparison with normal individuals, in depressed people this attention bias is manifested by increased amygdala responses to negative facial expressions (scary and sad) (Suslow et al., 2010; Victor et al., 2010) that could return to a normal response after treatment for depression (Godlewska, Norbury, Selvaraj, Cowen, \& Hamer, 2012). Stuhrmann, Suslow, \& Dannloeski (2011), who studied 20 pieces of research on face processes in depressed people, reported disorders in face processing networks that indicated mood processing bias in amygdala, insula, parahippocampal gyrus, fusiform, putamen, cingulare and orbitofrontal cortex. Modinos, Mechelli, Pettersson-Yeo, Allen, McGuire, \& Aleman (2013) found out that in depressed people, the function of brain areas, related to the emotions, i.e. the inferior frontal gyrus, including the anterior cingulate cortex, as well as both sides of the amygdala and insula, are increased to process sad emotional images. Chechko, Augustin, Zvyagintsev, Schneider, Habel, \& Kellermann (2013) believe that, in depressed people, the cortex involvement in the lateral prefrontal, parietal and extrastriate is decreased, in line with an increase in the limbic system (particularly the right amygdala), when processing emotional faces and words. At the same time, Kanske, Heissler, Schonfelder, \& Wessa (2012) discovered a decrease in amygdala response to negative emotional stimuli (not positive) and an increase in the function of the emotional regulation control network, including the posterior cingulate and lateral orbitofrontal cortex, while measuring neural responses to emotional images.

A review of the related literature shows that no research so far has studied whether attention bias, caused by face and image stimuli, could help in the diagnosis of depression. Some theoretical arguments show that human emotional faces are given priority over emotional words, but a few researchers have compared emotional faces with emotional images. To increase relevant information and to strengthen its theoretical and research foundations, the current enquiry intends to study the potential of attention bias as identified by two dot-probe tasks, using emotional face and emotional image stimuli in the diagnosis of depression. The research question is whether the attention bias identified by emotional face dot-probe tasks differs from the emotional image dot-probe task in predicting depression.

\section{Method}

This study is descriptive and co-relational in its nature. The subjects of the study included all those people aged 19 - 40 who had visited a psychology clinic in Tehran from 2011-2012. They were screened using an unstructured interview as per the 4th Edition of Diagnostic and Statistical Manual of Mental Disorders (DSMIV-TR), as well as the Beck Depression Inventory (cut off point of 21 and higher). Finally, eighty-two depressed patients were selected by means of convenience sampling. The subjects did two dot-probe tasks, using emotional faces and emotional images as stimuli.

\section{Instruments}

\section{Beck Depression Inventory (BDI)}

This test was developed by Beck and his colleagues. The test evaluates emotional, motivational, physical and vegetative symptoms, as well as recognition symptoms. Using the Spearman-Brown formula, Beck reported the test's validity as 0.93 . The questionnaire used has 21 questions, with four multiple answers for each question. The subjects were requested to draw a circle around the answer that described their feelings best in that particular week. Fata (1991) has reported the correlation coefficient between BDI and the Hamilton Depression Test for Iranian examinees as 0.66 . The validity and reliability of the test in both the healthy and clinical population was proved by a study conducted in Rouzbeh Hospital, affiliated to Tehran University of Medical Sciences (Kavyani, Mousavi, \& Mohit, 2001).

\section{Modified Dot-Probe Test of Emotional Faces and Emotional Images}

This is a modified version of the original test (MacLeod, Mathews, \& Tata, 1986) two versions of which were prepared for this study. In the first version, sad and neutral faces from the Nim Stim data bank (Tottenham et al., 2009) were used as stimuli. The stimuli in the second test consisted of depressive emotional images, which were selected from the international emotional images of depression (IAPS, Lang, Bradley \& Cuthbert, 1995). The images and a star $(*)$ (Figure 1) were presented in two rectangles that were placed 2 centimeters from the central fixation point of the monitor. The examinee was situated 50 centimeters away from the computer.

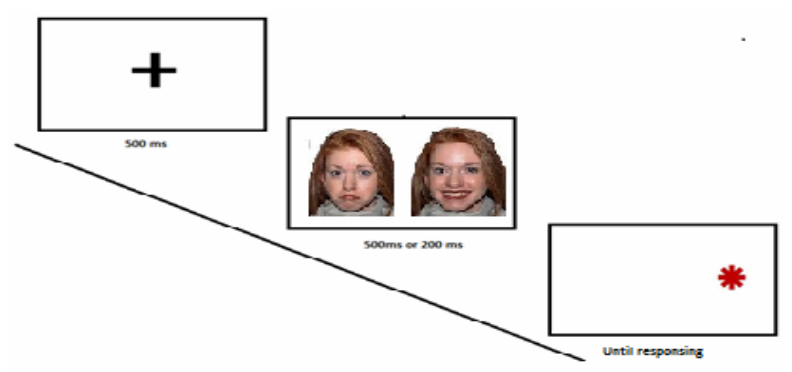

Figure 1.

Dotprobe task for assessing the attention bias toward two pairs of images. 
Firstly the empty rectangle and the fixation point $(+)$ were presented for the period of $500 \mathrm{~ms}$. Then two faces were shown on the left and right hand side of the monitor fixation point, for a period of $500 \mathrm{~ms}$. The subject had to use the arrows on the computer keyboard to show the star's direction. The computer recorded the response with a reaction time of up to $1 \mathrm{~min}$. The test was administered via a laptop computer. The total of correct responses (accuracy) and the average time used for responding to the questions (reaction time) in each presentation mode (congruent and incongruent), were calculated separately. The index of attention bias was calculated by subtracting the reaction time of the examinees, when the star is directed towards the face, from their reaction time, when the star shows the incorrect direction.

\section{Results}

As observed in Table 1, the attention bias toward the emotional face and the emotional image have a positive significant relationship with depression $(P<0.01)$. Thus, univariate regression analysis is presented later to compare the potential of the above-mentioned dot-probe tasks in predicting depression.

In Table 2, significant $F$ and positive $\beta$ coefficients show that the attention bias toward the emotional image could significantly predict depression $(P<0.01)$. The findings suggest that the high attention bias measured by the emotional image dot-probe task indicates deeper depression. According to the $\beta$ coefficient $(\beta=0.917)$ it could be stated that attention bias toward the emotional image determines $84 \%$ of the depression score variance. The regression equation is as follows:

Attention bias $=-30.819+($ Attention bias toward emotional image $\times 0.798)$.

In Table 3, a significant $F$ and a positive $\beta$ show that the attention bias toward the emotional image could significantly predict depression $(P<0.01)$. The findings suggest that the high attention bias measured by the emotional image dot-probe task indicates deeper depression. According to the $\beta$ coefficient $(\beta=0.785)$ it could be stated that the attention bias toward the emotional image determines $62 \%$ of the depression score variance. The regression equation is as follows:

Attention bias $=-17.652+($ Attention bias towards the emotional image $\times 0.440$ ).

To study whether there is a significant difference between the attention bias index with regard to the emotional face and

Table 1.

Descriptive characteristics and correlation coefficients relevant to depression and attention bias in two dot-probe tasks.

\begin{tabular}{|c|c|c|c|c|c|c|}
\hline \multirow[t]{2}{*}{ Variable } & & \multirow[b]{2}{*}{ Mean(sd) } & \multicolumn{2}{|c|}{ Attention bias } & \multicolumn{2}{|c|}{ Depression } \\
\hline & & & Face & Image & Face & Image \\
\hline \multirow{2}{*}{$\begin{array}{l}\text { Attention bias } \\
\text { index }\end{array}$} & Face & $-6.19(7.33)$ & 1 & - & $0.917^{*}$ & - \\
\hline & Image & $-5.33(6.81)$ & - & 1 & - & $0.785^{*}$ \\
\hline \multirow{2}{*}{ Depression } & Face & $28.66(7.97)$ & - & - & 1 & - \\
\hline & Image & $28.66(7.97)$ & - & - & - & 1 \\
\hline \multirow{2}{*}{$\begin{array}{c}\text { Reaction time, } \\
\text { congruent }\end{array}$} & Face & $5.33(3.30)$ & - & - & - & - \\
\hline & Image & $7.92(2.10)$ & - & - & - & - \\
\hline \multirow{2}{*}{$\begin{array}{l}\text { Reaction time, } \\
\text { incongruent }\end{array}$} & Face & $12.39(6.85)$ & - & - & - & - \\
\hline & Image & $13.25(6.82)$ & - & - & - & - \\
\hline
\end{tabular}

Note: ${ }^{*} P<0.01$.
Table 2.

Variance analysis and regression coefficients to predict attention bias using the emotional face dot-probe task.

\begin{tabular}{|c|c|c|c|c|c|c|}
\hline Source & Ss & Df & MS & & $\mathrm{F}$ & $P<$ \\
\hline Regression & 3919.56 & 1 & 3919.56 & & 421.33 & 0.0005 \\
\hline Residual & 744.21 & 80 & 9.30 & & & \\
\hline Criterion & Predictor & Constant & B & $\beta$ & $\mathrm{t}$ & $P<$ \\
\hline Depression & $\begin{array}{c}\text { Attention } \\
\text { bias index } \\
\text { (face) }\end{array}$ & -30.82 & 0.80 & 0.92 & 20.53 & 0.0005 \\
\hline
\end{tabular}

Table 3.

Variance analysis and regression coefficient to predict attention bias using the emotional image dot-probe task

\begin{tabular}{ccccccc}
\hline Source & Ss & Df & MS & F & $P<$ \\
\hline Regression & 1407.32 & 1 & 1407.32 & 128.77 & 0.0005 \\
Residual & 874.26 & 80 & 10.93 & & \\
Criterion & Predictor & Constant & B & $\beta$ & t & $P<$ \\
& $\begin{array}{c}\text { Attention } \\
\text { bias index } \\
\text { (image) }\end{array}$ & -17.66 & 0.44 & 0.79 & 11.35 & 0.0005 \\
\hline
\end{tabular}

the emotional image dot-probe tasks, the Fisher's Z-test was used. After converting the (r) coefficient scores to $(Z)$ coefficient scores, the $\mathrm{Z}$ Fisher score was $3.19(\mathrm{Z}=3.19, P=$ $0.0007)$. This shows that the difference was significant at the $P$ $<0.01$ level.

\section{Conclusion}

The research showed that both dot-probe tasks are significantly related to depression, and could even predict it. Compared to the emotional image dot-probe task, the significant $\mathrm{Z}$ Fisher score and the higher correlation coefficient and $\beta$ coefficient in the emotional face dot-probe task indicates that this task could predict depression more efficiently. This finding is in line with the following research in terms of the nerve plexus. Stuhrmann et al. (2011) and Modinos et al. (2013) identified the relevant areas of the brain involved in processing emotional faces and images in depressed people. Chechko et al. (2013) showed that in depressed people, the decrease in corticle involvement occurs in line with an increase in the limbic system response. Kanske et al. (2012) discovered a decrease in the amygdala response, and an increase in the cortex's function in processing emotional images in depressed people.

As earlier stated, attention bias makes the individual vulnerable to depression, and it also plays the key role in its onset and development. Thus, both dot-probe tasks used to measure attention bias could predict depression. On the other hand, depressed people have problems in processing sad emotional images and in calling for cognitive control from the higher cortical areas. This is done in a subliminal way, by the sub-cortical and paralimbic regions of the brain within the frontal-limbic nerve network (Japee, 2013). Subliminal processing that is independent of the cognitive analysis is considered a fast procedure. Thus, depressed people show a faster, more precise attention bias towards emotional faces (more negative attention bias index). On the other hand, the more negative attention bias index towards sad faces could indicate a greater degree of depression. 
Processing sad emotional images takes more time because the cortical regions are involved, and so thinking and cognitive analysis have more roles to play in this process. Thus, depressed people show a slower attention bias towards sad images (more positive attention bias). On the other hand, a more positive attention bias towards sad images contributes little to the diagnosis of depression. Thus dot-probe tasks that measure subliminal and unconscious processing (Japee, 2013) could diagnose and predict depression more efficiently when using emotional faces as stimuli.

To verify these research findings, one would suggest that future research employs brain imaging techniques.

\section{REFERENCES}

Baert, S., De Raedt, R., Schacht, R., \& Koster, E. H. V. (2010). Attentional bias training in depression: Therapeutic effects depend on depression severity. Journal of Behavioral Therapy Exp Psychiatry, 41, 265-274. doi:10.1016/j.jbtep.2010.02.004

Beck, A. T. (1976). Cognitive therapy and the emotional disorders. Oxford: International Universities Press.

Beck, A. T. (2008). The evolution of the cognitive model of depression and its neurobiological correlates. American Journal of Psychiatry, 165, 969-977. doi:10.1176/appi.ajp.2008.08050721

Beevers, C., Wells, T., Ellis, A., \& Fischer, K. (2009). Identification of emotionally ambiguous interpersonal stimuli among dysphoric and non-dysphoric individuals. Journal of Cognitive Therapy Research, 33, 283-290. doi:10.1007/s10608-008-9198-6

Beevers, C. G., \& Carver, C. S. (2003). Attentional bias and mood persistence as prospective predictors of dysphoria. Journal of Cognitive Therapy and Research, 27, 619-637.

doi:10.1023/A:1026347610928

Bouhuys, A., Bloem, G., \& Groothuis, T. (1995). Induction of depressed and elated mood by music influences the perception of facial emotional expressions in healthy subjects. Journal of Affective Disorders, 33, 215-226. doi:10.1016/0165-0327(94)00092-N

Bouhuys, A. L., Geerts, E., \& Gordijn, M. C. (1999). Depressed patients perceptions of facial emotions in depressed and remitted states are associated with relapse: A longitudinal study. Journal of Nervous Mental Disorder, 187, 595-602. doi:10.1097/00005053-199910000-00002

Browning, M., Holmes, E. A., Charles, M., Cowen, P. J., \& Hamer, C. J. (2012). Using attentional bias modification as a cognitive vaccine against depression. Journal of Biological Psychiatry, 72, 572-579. doi:10.1016/j.biopsych.2012.04.014

Chaleypanloo, G., Garoosi Farshi, M. T., \& Ghenaat Pisheh, Z. (2010). Comparing attention bias toward emotional faces in people suffering from social anxiety, Generalized Anxiety Disorder (GAD) as well as normal people. Journal of Behavioral Sciences, 4, 215-223.

Chechko, N., Augustin, M., Zvyagintsev, M., Schneider, F., Habel, U., \& Kellermann, T. (2013). Brain circuitries involved in emotional interference task in major depression disorder. Journal of Affective Disorders, 149, 136-145. doi:10.1016/j.jad.2013.01.013

Chen, Y. P., Ehlers, A., Clark, D. M., \& Mansell, W. (2002). Patients with generalized social phobia direct their attention away from faces. Journal of Behaviour Research and Therapy, 40, 677-687. doi:10.1016/S0005-7967(01)00086-9

Dimberg, U., Thunberg, M., \& Elmehed, K. (2000). Unconscious facial reaction to emotional facial expressions. Journal of Psychological science, 11, 86-89. doi:10.1111/1467-9280.00221

Fata, L. (1991). Comparing exposure and response prevention, clomipramine and their combination in treatment of obsessive compulsive disorder. Masters Dissertation, Tehran: Tehran Psychiatric Institute.

Fritzsche, A., Dahme, B., Gotlib, I. H., Joormann, J., Magnussen, H., Watz, H., Nutzinger, D. O., \& von Leupoldt, A. (2010). Specificity of cognitive biases in patients with current depression and remitted depression and in patients with asthma. Journal of Psychology Medicine, 40, 815-826. doi:10.1017/S0033291709990948
Godlewska, B. R., Norbury, R., Selvaraj, S., Cowen, P. J., \& Hammer, C. J. (2012). Short-term SSRI treatment normalizes amygdale hyperactivity in depression patients. Journal of Psychology Medicine, 42, 2609-2617. doi:10.1017/S0033291712000591

Gur, R. C., Erwin, R. J., Gur, R. E., Zwil, A. S., Heimberg, C., \& Kraemer, H. C. (1992). Facial emotion discrimination, II, behavioural findings in depression. Journal of Psychiatry Research, 42, 241-251. doi:10.1016/0165-1781(92)90116-K

Inoue, Y., Tonooka, Y., Yamada, K., \& Kanba, S. (2004). Deficiency of theory of mind in patients with remitted mood disorder. Journal of Affective Disorders, 82, 403-409.

Japee, L. M. (2013). An fMRI study of emotional face processing in adolescent major depression. Master Dissertation, Minneapolis, MN: University of Minnesota.

Joormann, J., \& Gotlib, I. H. (2007). Selective attention to emotional faces following recovery from depression. Journal of Abnormal Psychology, 116, 80-85. doi:10.1037/0021-843X.116.1.80

Kanske, P., Heissler, J., Schönfelder, S., \& Wessa, M. (2012). Neural correlates of emotion regulation deficits in remitted depression: The influence of regulation strategy, habitual regulation use, and emotional valence. Journal of NeuroImage, 61, 686-693. doi:10.1016/j.neuroimage.2012.03.089

Kavyani, H., Mousavi, A. S., \& Mohit, A. (2001). Interview and psychological test. Tehran: Institute for Cognitive Science Studies.

Kerr, N., Dunbar, R. I., \& Bentall, R. P. (2003). Theory of mind deficits in bipolar affective disorder. Journal of Affective Disorders, 73, $253-$ 259. doi: 10.1016/S0165-0327(02)00008-3

Koster, E. H. W., De Raedt, R., Goeleven, E., Franck, E., \& Crombez, G. (2005). Mood-congruent attention biases in dysphoria: Maintained attention and impaired attention disengagement from negative information. Journal of Emotion, 5, 446-455. doi: 10.1037/1528-3542.5.4.446

Koster, E. H. W., Leyman, L., De Raedt, R., \& Crombez, G. (2006). Cueing of visual attention by emotional facial expressions: The influence of individual differences in anxiety and depression. Journal of Personality and Individual Differences, 41, 329-339. doi:10.1016/j.paid.2005.12.022

Leung, K. K., Lee, T. M., Yip, P., Li, L. S., \& Wong, M. M. (2009). Selective attention biases of people with depression: Positive and negative priming of depression-related information. Journal of Psychiatry Research, 165, 241-251. doi:10.1016/j.psychres.2007.10.022

Levendosky, A. A., Okun, A., \& Parker, J. G. (1995). Depression and maltreatment as predictor of social competence and social problem-solving skills in school-age children. Journal of Child Abuse and Neglect, 19, 1183-1195. doi:10.1016/0145-2134(95)00086-N

Leyman, L., De Raedt, R., Schacht, R., \& Koster, E. H. W. (2006) Attention bias for angry faces in unipolar depression. Journal of Psychological Medicine, 37, 393-402. doi:10.1017/S003329170600910X

MacLeod, C., Mathews, A., \& Tata, P. (1986). Attentional bias in emotional disorders. Journal of Abnormal Psychology, 95, 15-20. doi:10.1037/0021-843X.95.1.15

MacLeod, C., \& Mathews, A. M. (1991). Cognitive experimental approaches to the emotional disorders. In P. R. Martin (Ed.), Handbook of behavior therapy and psychological science: An integrative approach (pp. 116-150). Elmsford, NY: Pergamon.

Modinos, G., Mechelli, A., Pettersson-Yeo, W., Allen, P., McGuire. P., \& Aleman, A. (2013). Pattern classification of brain activation during emotional processing in subclinical depression: psychosis proneness as potential confounding factor. PeerJ, 1, e42. doi: $10.7717 /$ peerj. 42

Mogg, K., \& Bradlley, B. P. (2002). Selective orienting of attention to makes threat faces in social anxiety. Journal of Behavioral research therapy, 40, 1403-14014. doi:10.1016/S0005-7967(02)00017-7

Peckham, A. D., McHugh, R. K., \& Otto, M. W. (2010). A metaanalysis of the magnitude of biased attention in depression. Journal of Depression and Anxiety, 27, 1135-1142. doi:10.1002/da.20755

Schmukle, S. C. (2005). Unreliability of the dot probe task. European Journal of Personality, 19, 595-605. doi:10.1002/per.554

Sears, C. R., Newman, K. R., Ference, J. D., \& Thomas, C. L. (2011). Attention to emotional images in previously depressed individuals: 


\section{B. AJILCHI, V. NEJATI}

an eye-tracking study. Journal of Cognitive Therapy Research, 35, 517-528. doi:10.1007/s10608-011-9396-5

Segal, Z. V., Gemar, M., \& Williams, S. (1999). Differential cognitive response to a mood challenge following successful cognitive therapy or pharmacotherapy for unipolar depression. Journal of Abnormal Psychology, 108, 3-10. doi:10.1037/0021-843X.108.1.3

Staugaard, S. R. (2009). Reliability of two versions of the dot-probe task using photographic faces. Journal of Psychology Science Quarterly, 51, 339-350.

Stuhrmann, A., Suslow. T., \& Dannlowski, U. (2011). Facial emotion processing in major depression: A systematic review of neuroimaging findings. Journal of Biology of Mood \& Anxiety Disorders, 1, 117.

Suslow, T., Konrad, C., Kugel, H., Rumstadt, D., Zwitserlood, P., Schoning, S., Ohrmann, P., \& Dannlowski, U. (2010). Automatic mood congruent amygdale responses to masked facial expressions in major depression. Journal of Biological Psychiatry, 67, 155-160. doi:10.1016/j.biopsych.2009.07.023

Teasdale, J. D. (1988). Cognitive vulnerability to persistent depression. Journal of Cognition and Emotion, 2, 247-274. doi:10.1080/02699938808410927

Victor, T. A., Furey, M. L., Fromm, S. J., Ohman, A., \& Drevets, W. C. (2010). Relationship between amygdale response to masked faces and mood state and treatment in major depression disorder. Archive of General Psychiatry, 67, 1128-1138. doi:10.1001/archgenpsychiatry.2010.144

Wang, Y., Wang, Y. G., Chen, S., Zhu, C., \& Wang, K. (2008). Theory of mind disability in major depression with or without psychotic symptoms: A componential view. Journal of Psychiatry Research, $161,153-161$

Wells, T. T., \& Beevers, C. G. (2009). Biased attention and dysphoria: Manipulating selective attention reduces subsequent depressive symptoms. Journal of Cognition \& Emotion, 24, 719-728. doi: $10.1080 / 02699930802652388$

William, J. M. G., \& Oaksford, M. R. (1992). Cognitive science, anxiety, and depression: From experiments to connectionism. In D. J. Stein (Ed.), Journal of Cognitive Science and Clinical Disorders (pp. 129-150). San Diego, CA: Academic Press. 